\title{
PELATIHAN MANAJEMEN PEMASARAN INDUSTRI RUMAH TANGGA RAKET TENIS MEJA
}

\author{
Tri Yulistyawati Evelina ${ }^{1)}$, Shinta Maharani Trievena ${ }^{2)}$, Ahmad Fauzi $^{3 \text { ) }}$ \\ Jurusan Administrasi Niaga, Politeknik Negeri Malang \\ Email: trievelina@gmail.com, shitamaharanitrievena@yahoo.co.id, fauzipoltek@gmail.com,
}

\begin{abstract}
Abstrak
Industri Rumah Tangga Raket Tenis Meja Kota Malang merupakan kumpulan anggota rumah tangga, yang tugas utamanya sebagai istri adalah mengelola semua pendapatan/penerimaan baik penerimaan rutin maupun tidak rutin dan pengeluaran rutin maupun pengeluaran tidak rutin sehari-hari untuk keperluan keluarganya. Masalah anggota Industri Rumah Tangga Raket Tenis Meja adanya pos-pos yang over budget sehingga terjadi defisit keuangan pada akhir bulan atau adanya kebutuhan yang tidak terpenuhi. Kondisi diatas seharusnya dapat dihindari apabila dalam pengelolaan dana keluarga dilakukan dengan perencanaan yang tepat. Salah satu yang diusulkan kepada anggota adalah Pelatihan Manajemen Pemasaran .

Permasalahan yang ditemukan a) Kurangnya pemahaman pentingnya Manajemen Pemasaran , b) Kurangnya pengetahuan dan keterampilan dalam Manajemen Pemasaran dalam merencanakan dan mencapai sasaran keuangan. Solusi yang ditawarkan adalah a) Peningkatan pengetahuan dan keterampilan Manajemen Pemasaran , b) Pelatihan Manajemen Pemasaran .Kontribusi mendasar pada mitra adalah a) Penyuluhan pentingnya Manajemen Pemasaran , b) Sharing dan diskusi pengalaman dalam Manajemen Pemasaran , c) Pelatihan Manajemen Pemasaran Berbasis Online,
\end{abstract}

Kata Kunci : Manajemen Pemasaran, Industri kecil, Pelatihan Pemasaran

\begin{abstract}
Home Industry Malang City Table Tennis Racket is a collection of household members, whose main task as a wife is to manage all income / revenues, both routine and non-routine receipts and routine and nonroutine expenses for family needs. The problem of members of the Table Tennis Racket Household Industry is that there are over-budget posts, resulting in a financial deficit at the end of the month or an unmet need. The above conditions should be avoided if the management of family funds is carried out with proper planning. One that is proposed to members is Marketing Management Training.Problems found a) Lack of understanding the importance of Marketing Management, b) Lack of knowledge and skills in Marketing Management in planning and achieving financial goals. The solutions offered are a) Improvement of Marketing Management knowledge and skills, b) Marketing Management Training. Fundamental contributions to partners are a) Extension of the importance of Marketing Management, b) Sharing and discussion of experience in Marketing Management, c) Online Marketing Management Training,
\end{abstract}

Keywords: Marketing Management, Small Industry, Marketing Training

\section{PENDAHULUAN}

Badan Pusat Statistik (BPS) mencatat hasil pendaftaran Sensus Ekonomi 2016 (SE2016) sebanyak 26,71 juta usaha atau perusahaan. Bila dibedakan menurut skala usaha sebanyak 26,26 juta perusahaan atau 98,33\% berskala Usaha Menengah Kecil UMK dan 0,45 juta perusahaan atau 1,67\% berskala usaha Menengah Besar (UMB). Perkembangan usaha tersebut dari tahun ke tahun meningkat. Menurut Sensus
Ekonomi 2006 (SE2006) jumlah usaha/perusahaan meningkat $17,51 \%$ dari 22,73 juta menjadi 26,71 juta di tahun 2016 (https://economy.okezone.com, 2017). Artinya, ada 3,98 juta perusahaan baru dalam 10 tahun terakhir, jumlah perusahaannya banyak, tapi kecil-kecil.

Usaha-usaha kecil tersebut salah satunya adalah industri rumah tangga. Industri rumah tangga (home industry) 
adalah industri yang menggunakan tenaga kerja kurang dari empat orang. Ciricirinya, yaitu memiliki modal yang sangat terbatas, tenaga kerja berasal dari anggota keluarga, dan pemilik atau pengolah industri biasanya kepala rumah tangga itu sendiri atau anggota keluarganya. Para pengusaha industri kecil dalam mengembangkan bisnis kadangkala menghadapi masalah manajemen pemasaran, yaitu masalah kemasan, label, merek, harga, distribusi dan promosi. Begitu juga dengan industri rumah tangga Raket Tenis Meja yang berlokasi di Lawang juga menghadapi masalah manajemen pemasaran. Selama ini pemasaran produk hanya melalui mitra distributor di Surabaya sebanyak 5 (lima) mitra. Sedangkan harapannya juga dapat menjangkau pemasaran langsung ke tangan konsumen.

Berdasarkan uraian di atas, pengusul berniat untuk memecahkan permasalahan yang ada dengan mengusulkan Pelatihan Manajemen Pemasaran dengan tujuan untuk peningkatan pengetahuan dan keterampilan dalam memasarkan produk bagi Industri Rumah Tangga Raket Tenis Meja Kota Malang.

Merujuk pada analisis situasi di atas permasalahan mitra dalam kegiatan PKM ini adalah: 1) Kurangnya pemahaman pentingnya Manajemen Pemasaran bagi Industri Rumah Tangga Raket Tenis Meja Kota Malang. 2) Kurangnya pengetahuan dan keterampilan dalam Manajemen Pemasaran dalam merencanakan dan mencapai sasaran keuangan bagi Industri Rumah Tangga Raket Tenis Meja Kota Malang.

\section{TINJAUAN PUSTAKA}

\section{Pengertian Manajemen Pemasaran}

Kotler (2005; p.11) mendefinisikan manajemen pemasaran sebagai seni dan ilmu memilih pasar sasaran dan meraih, mempertahankan, serta menumbuhkan pelanggan dengan menciptakan, menghantarkan dan mengkomunikasikan nilai pelanggan yang unggul. Pengertian lainnya dikemukakan oleh Armstrong dan Kotler (2012; p.29) yang menyatakan bahwa manajemen pemasaran adalah serangkaian proses yang dilakukan oleh perusahaan untuk menciptakan suatu nilai bagi para pelanggan dan membangun hubungan yang kuat dengan mereka agar tercipta suatu nilai dari para pelanggan tersebut.

\section{Tugas Manajemen Pemasaran}

Tugas-tugas manajer pemasaran dapat dilihat dari segi fungsi manajemen yang dilakukan dalam bidang pemasaran, yaitu bagaimana proses manajemen itu dijalankan untuk mengubah sumbersumber menjadi produk yang dapat memenuhi kebutuhan manusia. Tugastugas itu antara lain :

a) Mempelajari kebutuhan dan keinginan konsumen

b) Mengembangkan suatu konsep produk yang ditujukan untuk memuaskan/melayani kebutuhan

c) Membuat desain produk

d) Mengembangkan pembungkusan dan merk

e) Menetapkan harga agar memperoleh

f) Return on investment yang layak

g) Mengatur distribusi

h) Memeriksa penjualan

i) Menciptakan komunikasi pemasaran yang efektif dengan menggunakan media atau cara lain yang tepat

\section{Permasalahan dalam Manajemen Pemasaran}

Berdasarkan definisi pemasaran (marketing) oleh Kotler (2005) di atas, maka dapat diketahui bahwa masalah inti kegiatan pemasaran adalah masalah bauran pemasaran (marketing mix phenomena). Masalah bauran pemasaran (marketing mix phenomena) ialah kombinasi empat masalah kegiatan yang merupakan masalah inti kegiatan pemasaran yakni masalah 
produk (product phenomena), masalah harga (price phenomena), masalah distribusi (distribution /place phenomena) dan masalah promosi (promotion phenomena).

Masalah bauran pemasaran (marketing mix phenomena) ini sering disebut masalah empat $\mathrm{P}$ yaitu product phenomena, price phenomena, place phenomena, dan promotion phenomena yaitu:

- Pertama, masalah produk (product phenomena). Produk (product) adalah segala sesuatu yang dapat ditawarkan ke suatu pasar untuk memuaskan keinginan atau kebutuhan (Kotler, 2002) termasuk kemasan, merek, label, warna, prestise perusahaan, prestise pengencer, pelayanan perusahaan dan pelayanan pengencer. Produk yang dipasarkan meliputi barang fisik, jasa, pengalaman, peristiwa, orang, tempat, properti, organisasi, dan gagasan.

- Kedua, masalah harga (price phenomena). Swastha (1981) dalam bukunya Azas-azas Marketing mengemukakan bahwa harga (price) adalah jumlah uang (ditambah beberapa barang kalau mungkin) yang dibutuhkan untuk mendapatkan sejumlah barang beserta pelayanannya.

- Ketiga, masalah distribusi (distribution / place phenomena). Swastha (1981) dalam buku AzasAzas Marketing mengemukakan bahwa distribusi (distribution) adalah saluran yang digunakan oleh produsen untuk menyalurkan barang dari produsen kepada konsumen.

- Keempat, masalah promosi (promotion phenomena). Swastha (1981) dalam buku dan Azas-Azas Marketing mengemukakan bahwa promosi (promotion) adalah arus informasi satu arah yang dibuat untuk mengarahkan konsumen untuk membeli.
Berdasarkan pada permasalahan mitra yang telah dijelaskan yaitu a) Kurangnya pemahaman pentingnya manajemen pemasaran bagi Industri Rumah Tangga Raket Tenis Meja Kota Malang serta, b) Kurangnya pengetahuan dan keterampilan dalam manajemen pemasaran dalam memasarkan produk, karena pemasaran terbatas hanya pada distributor saja tidak menjangkau langsung ke tangan konsumen. Selanjutnya pelatihan manajemen pemasaran dengan fokus pada pentingnya manajemen pemasaran dan peningkatan pemasaran produk sehingga dapat langsung menjangkau konsumen, tidak hanya mengandalkan pada distributor saja

\section{SOLUSI KEGIATAN}

Rencana kegiatan PkM ini disusun secara logis, mendasarkan pada solusi yang ditawarkan. Setiap solusi harus diakses dengan aktivitas sehingga setiap permasalahan akan mendapatkan penanganan yang jelas.

\section{Tabel 1. Solusi dan Rencana Kegiatan bagi Industri Rumah Tangga Raket Tenis Meja}

\begin{tabular}{|c|l|l|}
\hline No. & \multicolumn{1}{|c|}{ Solusi } & \multicolumn{1}{c|}{ Aktivitas } \\
\hline 1. & $\begin{array}{l}\text { Peningkatan } \\
\text { pengetahuan } \\
\text { dan } \\
\text { keterampilan } \\
\text { Manajemen } \\
\text { Pemasaran }\end{array}$ & $\begin{array}{l}\text { - Penyuluhan } \\
\text { pentingnya } \\
\text { Manajemen } \\
\text { Pemasaran }\end{array}$ \\
& $\begin{array}{l}\text { - Sharing dan diskusi } \\
\text { pengalaman dalam } \\
\text { Manajemen } \\
\text { Pemasaran }\end{array}$ \\
\hline 2. & $\begin{array}{l}\text { Pelatihan } \\
\text { Manajemen } \\
\text { Pemasaran }\end{array}$ & $\begin{array}{l}\text { - Pelatihan } \\
\text { Manajemen } \\
\text { Pemasaran } \\
\end{array}$ \\
& & $-\begin{array}{l}\text { Pendampingan } \\
\text { Manajemen } \\
\text { Pemasaran }\end{array}$ \\
\hline
\end{tabular}




\section{METODE PELAKSANAAN \\ Khalayak Sasaran}

Khalayak sasaran pelatihan ini adalah Industri Rumah Tangga Raket Tenis Meja Kota Malang

\section{Metode PkM}

Dalam melaksanakan kegiatan PkM ini, terdapat metode pelaksanaan sebagai berikut:

\section{Metode Pendekatan}

Pendekatan yang digunakan adalah pelatihan dan pendampingan Manajemen Pemasaran serta pendampingan.

\section{Rencana Kegiatan}

Pada pengabdian ini disusunlah rencana kegiatan yang dijelaskan pada Tabel 2 . Solusi dan Rencana Kegiatan.

\section{Tabel 2. Solusi dan Rencana Kegiatan bagi Industri Rumah Tangga Raket Tenis Meja}

\begin{tabular}{|c|c|c|}
\hline No. & Solusi & Aktivitas \\
\hline 1. & $\begin{array}{l}\text { Peningkatan } \\
\text { pengetahuan dan } \\
\text { keterampilan } \\
\text { Manajemen } \\
\text { Pemasaran }\end{array}$ & $\begin{array}{l}\text { - Penyuluhan } \\
\text { pentingnya } \\
\text { Manajemen } \\
\text { Pemasaran } \\
\text { - Sharing dan diskusi } \\
\text { pengalaman dalam } \\
\text { Manajemen } \\
\text { Pemasaran }\end{array}$ \\
\hline 2. & $\begin{array}{l}\text { Pelatihan } \\
\text { Manajemen } \\
\text { Pemasaran }\end{array}$ & $\begin{array}{l}\text { - Pelatihan Manajemen } \\
\text { Pemasaran } \\
\text { - Pendampingan } \\
\text { Manajemen } \\
\text { Pemasaran }\end{array}$ \\
\hline
\end{tabular}

\section{Partisipasi Mitra}

Mitra dalam kegiatan ini terdiri dari Ketua Industri Rumah Tangga Raket Tenis Meja Kota Malang. Komitmen mitra pada program PkM sangat tinggi. Hal ini dapat diketahui dari antusiasme dalam mengikuti diskusi proposal kegiatan ini. Bentuk partisipasi yang diberikan antara lain :
- Kesediaan diadakan penyuluhan pentingnya Manajemen Pemasaran

- Kesediaan untuk saling sharing dan diskusi pengalaman dalam Manajemen Pemasaran

- Kesediaan untuk dilatih dan didampingi dalam pelatihan Manajemen Pemasaran

- Kesediaan untuk menyediakan tempat pertemuan untuk koordinasi

\section{Desain Pelatihan}

Berikut ini adalah desain pelatihan pada Tabel 3.

\section{Tabel 3. Desain Pelatihan Manajemen Pemasaran}

\begin{tabular}{|c|c|c|}
\hline $\mathrm{Na}$ & $\underset{\text { Detatilan }}{\text { Detain }}$ & Iraian \\
\hline 1 & Judul Keguation & Pelatihan Slanijemen Petaasarun Berhasis Online \\
\hline 2. & Pelaksanaan & $\begin{array}{ll}\text { Tangenal } & \text { Mingen, } 8 \text { Agustus } 2019 \\
\text { Pukuf } & 15,00-17,00 \mathrm{Wit}\end{array}$ \\
\hline 3) & Peserta & 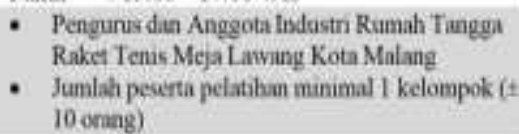 \\
\hline 4 & $\begin{array}{l}\text { Materi } \\
\text { Pelatihan }\end{array}$ & 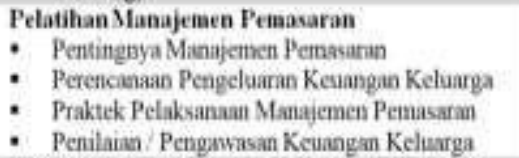 \\
\hline 5. & Pemateri & $\begin{array}{l}\text { TIM PKM Jurusun Administrasi Naga Politeknik } \\
\text { Negeri Maliang Tahan } 2019\end{array}$ \\
\hline
\end{tabular}

\section{HASIL DAN PEMBAHASAN \\ Hasil}

Sesuai dengan metode PKM yang dirancang, maka pelaksanaan kegiatan pengabdiannya sebagai berikut:

1. Peningkatan pengetahuan dan keterampilan Manajemen Pemasaran Mengidentifikasi sumber daya yang ada, selanjutnya mengusulkan pelatihan Manajemen Pemasaran yang akan diangkat sebagai pilot project. Pada kegiatan pengabdian ini dimulai dengan melakukan diskusi dengan beberapa pengurus Industri Rumah Tangga Raket Tenis Meja. 


\section{Pelaksanaan pelatihan Manajemen Pemasaran}

Selanjutnya setelah dilakukan pra pelatihan yang dilanjutkan dengan menyusun desain pelatihan, langkah selanjutnya adalah melaksanakan pelatihan. Pelatihan Manajemen Pemasaran bagi anggota Industri Rumah Tangga Raket Tenis Meja Kota Malang.

\section{Pembahasan}

Pelatihan Manajemen Pemasaran bagi anggota Industri Rumah Tangga Raket Tenis Meja Kota Malang, pelatihan ini adalah rekomendasi dari para pengurus dari Industri Rumah Tangga Raket Tenis Meja. Selanjutnya dari hasil pelatihan diatas harapannya dapat memberikan dasar dalam mengelola Manajemen Pemasaran bagi anggota Industri Rumah Tangga Raket Tenis Meja Kota Malang. Selain itu dapat memberikan dampak yang positif bagi pengelolaan keluarga ke depannya. Selanjutnya dari kegiatan ini nantinya dapat bermanfaat sebagai :

1. Masukan untuk mengembangkan program pengelolaan dan pengembangan keluarga

2. Masukan dalam kegiatan ini.

Dalam kegiatan ini, terdapat juga kekurangan-kekurangan yang perlu diperbaiki untuk pelatihan ke depannya :

1. Karena keterbatasan waktu dan tenaga, pelatihan ini diselenggarakan dalam waktu yang relatif singkat, padahal peserta sebenarnya sangat antusias untuk menggali lagi materimateri mengenai Manajemen Pemasaran .

2. Jumlah peserta yang terbatas, hanya dibatasi sebanyak 1 (satu) Kelompok atau \pm 10 orang,

3. Beberapa peserta belum dapat mempraktekkan materi yang disampaikan secara langsung karena keterbatasan waktu dan tenaga.
Berikut ini adalah beberapa dokumentasi kegiatan pelatihan manajemen Pemasaran Online yang telah dilakukan pada anggota Industri Rumah Tangga Raket Tenis Meja

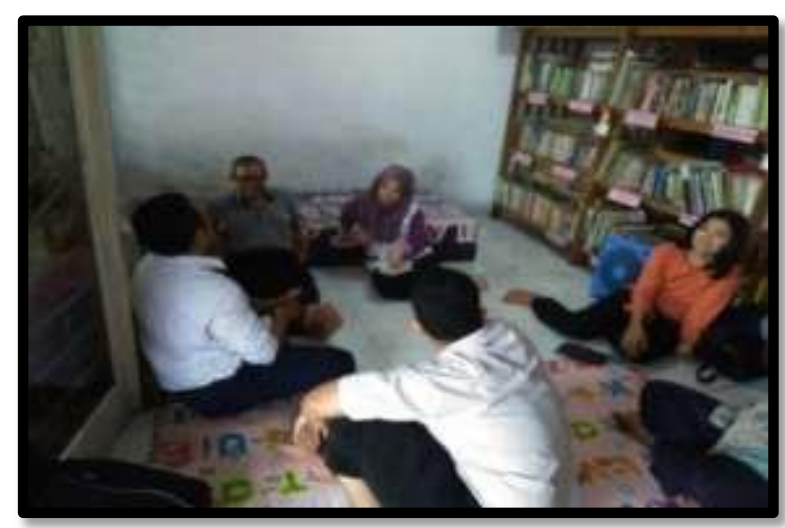

Gambar 1. Sharing dan diskusi pengalaman dalam Manajemen Pemasaran

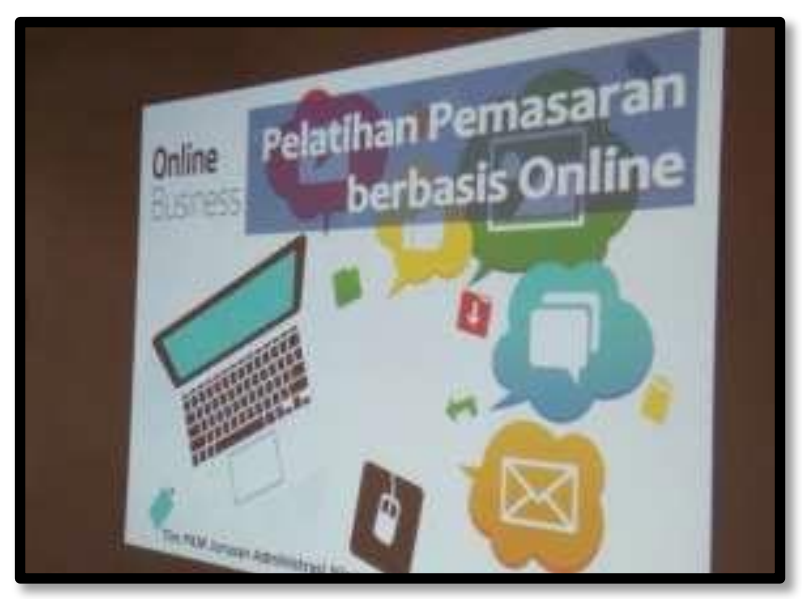

Gambar 2. Dokumentasi Kegiatan 1

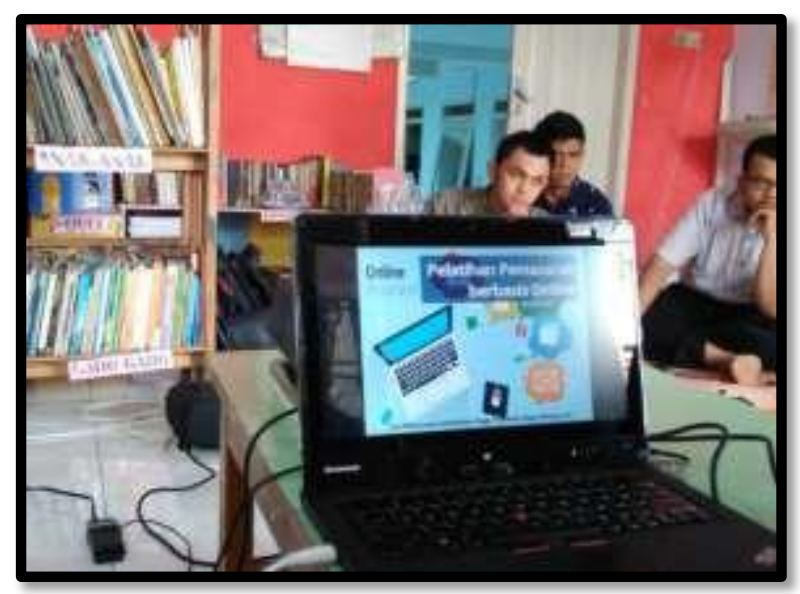

Gambar 3. Dokumentasi Kegiatan 2 


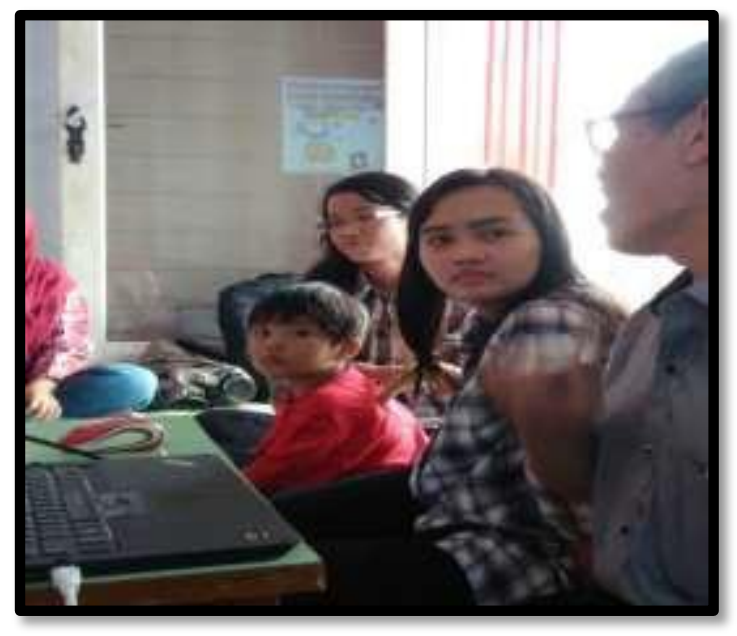

Gambar 4. Dokumentasi Kegiatan 3

\section{PENUTUP \\ Kesimpulan}

Dari kegiatan pengabdian kepada masyarakat dapat disimpulkan atas kegiatan yang telah dilaksanakan, sebagai berikut:

1. Tujuan dari kegiatan pengabdian ini adalah untuk memberikan pengetahuan dan ketrampilan bagi anggota rumah tangga dalam mengelola Manajemen Pemasaran.

2. Selanjutnya manfaat yang diharapkan adalah dapat memberikan penyuluhan pentingnya Manajemen Pemasaran, dapat sharing dan diskusi pengalaman dalam Manajemen Pemasaran, memberikan pelatihan Manajemen Pemasaran, serta pendampingan Manajemen Pemasaran bagi anggota rumah tangga Industri Rumah Tangga Raket Tenis Meja Kota Malang

3. Berdasarkan metode PKM yang ditempuh untuk mengatasi masalah, yaitu:

\section{- Pra Pelatihan, \\ - Design Pelatihan \\ - Pelaksanaan pelatihan}

3. Pelatihan yang diselenggarakan adalah pelatihan Manajemen Pemasaran yang diikuti oleh anggota rumah tangga Industri Rumah Tangga Raket Tenis Meja Kota Malang, dengan materi sebagai berikut :

- Pentingnya Manajemen Pemasaran

- Perencanaan Pengeluaran Keuangan Keluarga

- Praktek Pelaksanaan Manajemen Pemasaran

- Penilaian / Pengawasan Keuangan Keluarga

\section{Saran}

Selanjutnya berdasarkan pembahasan dan kesimpulan yang telah dijelaskan pada bab sebelumnya, maka dapat dikemukakan saran sebagai berikut:

1. Para peserta pelatihan ketrampilan kerja sangat antusias dalam mengikuti kegiatan ini, harapannya dapat dilakukan pelatihan kembali secara berkesinambungan dengan materi berikutnya, misalnya Pelatihan Makanan Sehat bagi Keluarga.

2. Menambah jumlah kuota peserta pelatihan yang mengikuti pelatihan

3. Waktu pelatihan ditambah kembali

\section{DAFTAR PUSTAKA}

Arnesih. (2016) Strategi Manajemen Keuangan Dalam Rumah Tangga (Berbasis Ekonomi Syariah ). Historia, Volume 10, Februari

Manullang. (1981). Pengantar Ekonomi Perusahaan. Yogyakarta: Liberty.

Pearce dan Robinson. (1997). Manajemen Strategik. (terjemahan Agus Maulana). Jakarta: Binarupa Aksara.

Syarifuddin, Hidayat. Analisis Manajemen Keuangan, Tekanan Ekonomi,Strategi koping dan Tingkat kesejahteraan Keluarga Nelayan di Desa Cikahuripan Kecamatan Cisolok Kota Batang. Skripsi di Institut Pertanian Bogor. 2012. 